\title{
Growth Mechanism of Electrodeposited Fe, Co and Ni Nanowires in the Form of Self-Assembled Arrays at Fixed Potential
}

\author{
Tahir Mehmood ${ }^{1, *}$, Aiman Mukhtar, Babar Shahzad Khan, Kaiming $\mathrm{Wu}^{2, *}$
}

The State Key Laboratory of Refractories and Metallurgy, Hubei Province Key Laboratory of Systems Science in Metallurgical Process, International Research Institute for Steel Technology, Wuhan University of Science and Technology, Wuhan 430081, P. R. China

E-mail: tahir10621@yahoo.com, wukaiming@wust.edu.cn

doi: $10.20964 / 2016.08 .36$

Received: 28 January 2016 / Accepted: 25 April 2016 / Published: 7 July 2016

The growth mechanism of electrodeposited $\mathrm{Fe}$, $\mathrm{Ni}$ and Co nanowires has been investigated by X-ray diffractometry, scanning electron microscopy and electrochemistry. It is found that the current density for deposition of $\mathrm{Fe}$ nanowires is higher than that of $\mathrm{Co}$ and $\mathrm{Ni}$ nanowires under the same overpotential, $\mathrm{pH}$, concentration of metal ions and temperature. Using the electron tunneling theory, this phenomenon has been ascribed to the higher charge transfer coefficient of Fe than that of Co and Ni.

Keywords: Nanostructure; electrodeposition; current density; work function

\section{FULLTEXT}

(C) 2016 The Authors. Published by ESG (www.electrochemsci.org). This article is an open access article distributed under the terms and conditions of the Creative Commons Attribution license (http://creativecommons.org/licenses/by/4.0/). 